\title{
Diverse Patterns of Odor Representation by Neurons in the Anterior Piriform Cortex of Awake Mice
}

\author{
Cheng Zhan ${ }^{1,2}$ and Minmin Luo ${ }^{2,3}$ \\ ${ }^{1}$ Britton Chance Center for Biomedical Photonics, Wuhan National Laboratory for Optoelectronics-Huazhong University of Science and Technology, \\ Wuhan, Hubei, 430074, China, ${ }^{2}$ National Institute of Biological Sciences, Beijing 102206, China, and ${ }^{3}$ School of Life Sciences, Tsinghua University, Beijing \\ 100084, China
}

The mammalian piriform cortex receives direct synaptic input from the olfactory bulb and is likely the locus for the formation of odor percept. It remains unclear how individual cortical neurons encode olfactory information in unanesthetized animals. By single-cell recordings from head-restrained awake mice, we studied the odor response profiles of individual neurons in the anterior piriform cortex (aPCX). Neurons were juxtacellularly labeled, and their cell types were determined by their morphology and neurotransmitter phenotypes. We found a considerable level of variability in selectivity patterns among pyramidal neurons (PNs). Approximately one-quarter of PNs were broadly activated by structurally dissimilar odorants, whereas the excitations to the rest of PNs were highly selective. Broad inhibition was only observed from a subpopulation of PNs. GABAergic neurons displayed nonselective excitatory responses to test odorants and rarely exhibited inhibition. In contrast, non-GABAergic nonpyramidal neurons in the deep layer tended to be strongly inhibited by multiple different odorants. Our findings suggest that odor representation is accomplished by both broadly tuned and narrow-tuned PNs in the aPCX of awake animals. In addition, various types of interneurons may play different roles in the intracortical processing of olfactory information.

\section{Introduction}

The mammalian olfactory system can perceive a vast number of odor stimuli. The strategies of encoding odor signals appear different at distinct processing stages. In the mouse main olfactory epithelium, odorants are detected by millions of olfactory sensory neurons (OSNs), each of which expresses only 1 of $>1000$ olfactory receptor (OR) genes (Buck and Axel, 1991; Godfrey et al., 2004; X. Zhang and Firestein, 2007). The axons of OSNs expressing a specific OR typically converge onto two spatially stereotypical glomeruli in the main olfactory bulb (MOB) (Ressler et al., 1994; Vassar et al., 1994; Mombaerts et al., 1996). An odorant activates multiple ORs and produces discrete spatial patterns of glomerular activation (Malnic et al., 1999; Rubin and Katz, 1999; Uchida et al., 2000; Wachowiak and Cohen, 2001; Soucy et al., 2009). Within each glomerulus, a set of 25-50 mitral/tufted cells receive their primary excitatory input from OSNs, and their response selectivity likely reflects that of their associated OR (Mori et al., 1999; Shepherd et al., 2004; Tan et al., 2010). Mitral/tufted cells then project their axons to the piriform cortex (PCX) (Price and Powell, 1970).

How does the PCX encode odor information? Studies show that an odorant activates neurons sparsely distributed across the

Received Aug. 19, 2010; revised Sept. 24, 2010; accepted 0ct. 10, 2010.

This work is supported by the China Ministry of Science and Technology 973 Grant 2010 CB833902 and 863 Grant 2008AA022312 (M.L.). We thank Yuchio Yanagawa (Gunma University and Solution-Oriented Research for Science and Technology, Japan Science and Technology Agency, Maebashi, Japan) for GAD67-GFP mice.

Correspondence should be addressed to Minmin Luo, National Institute of Biological Sciences, 7 Science Park Road, Zhongguancun Life Science Park, Beijing 102206, China. E-mail: luominmin@nibs.ac.cn.

DOI:10.1523/JNEUROSCI.4400-10.2010

Copyright $\odot 2010$ the authors $\quad 0270-6474 / 10 / 3016662-11 \$ 15.00 / 0$
PCX without an obvious spatial pattern (Illig and Haberly, 2003; Stettler and Axel, 2009). Moreover, both calcium imaging and electrophysiological recordings reveal that individual PCX neurons can respond to structurally dissimilar odorants (Wilson, 2000, 2001; Rennaker et al., 2007; Yoshida and Mori, 2007; Poo and Isaacson, 2009; Stettler and Axel, 2009). The interpretation of previous observations is limited by two key technical concerns. First, recordings and imaging are typically performed in anesthetized animals, and anesthetics can exert side effects on neuronal dynamics and olfactory responses in both the MOB and the PCX (Friedberg et al., 1999; Murakami et al., 2005; Rinberg et al., 2006; Wilson, 2010). Second, neurons of diverse morphological features are present in the PCX, and different types of neurons can exhibit highly distinct olfactory tunings (Poo and Isaacson, 2009). However, most studies do not distinguish the response properties of different cells types.

To understand how olfactory signals are processed and encoded by the PCX, it is critical to examine the response properties of individual neurons of specific cell types from awake animals. By performing single-cell recordings from head-restrained awake mice, we examined the neuronal response profiles in the anterior piriform cortex (aPCX), which represents one of the major olfactory cortical areas. Recordings from awake animals exclude the effects induced by anesthetics on olfactory responses. Cells were juxtacellularly labeled, and their cell types were identified by neuronal morphology and neurotransmitter phenotypes. Our results reveal distinct response profiles for cells of different morphology and neurotransmitters. More interestingly, we observed highly variable selectivity patterns among pyramidal neurons, the principle neurons 


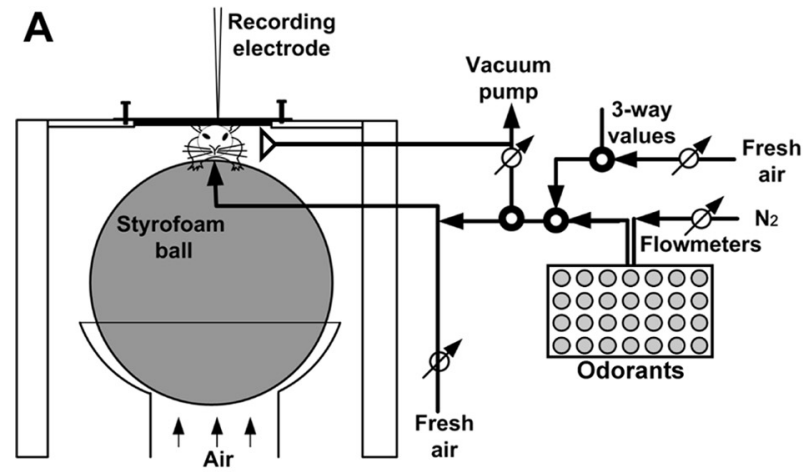

B

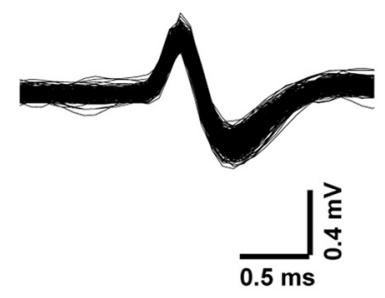

C
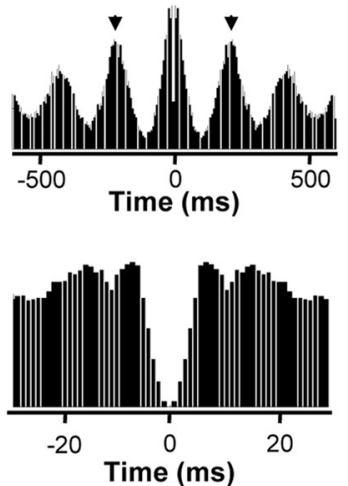

D
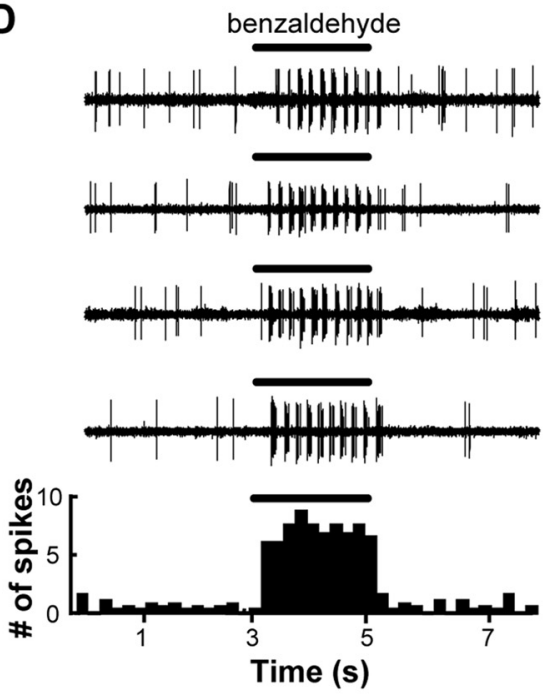
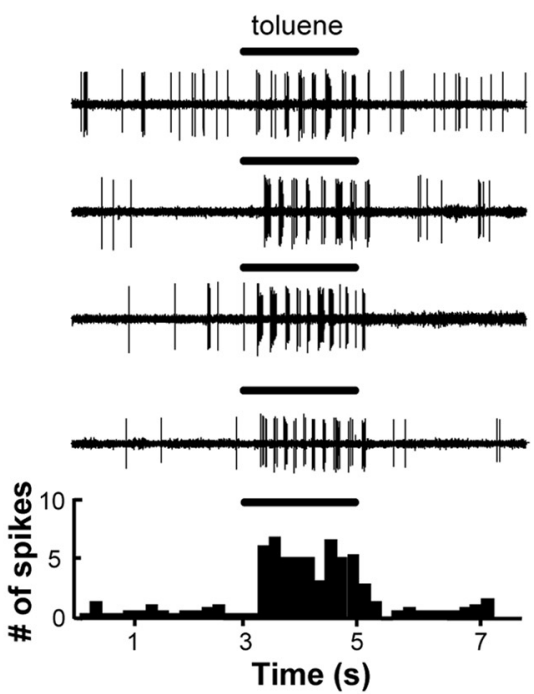
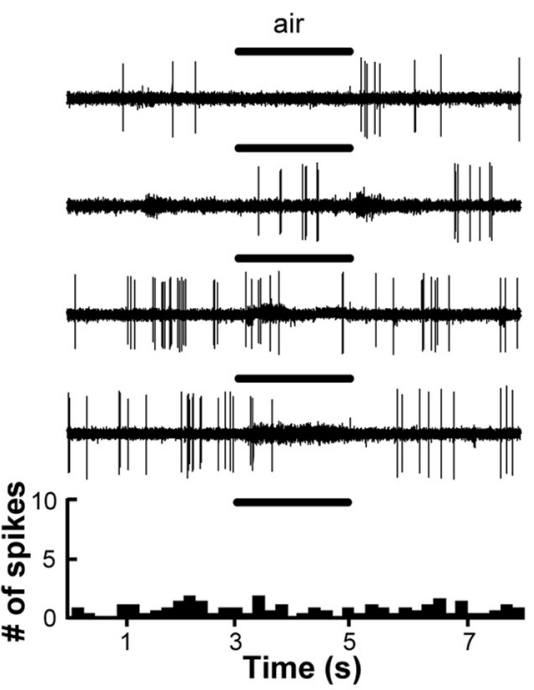

E
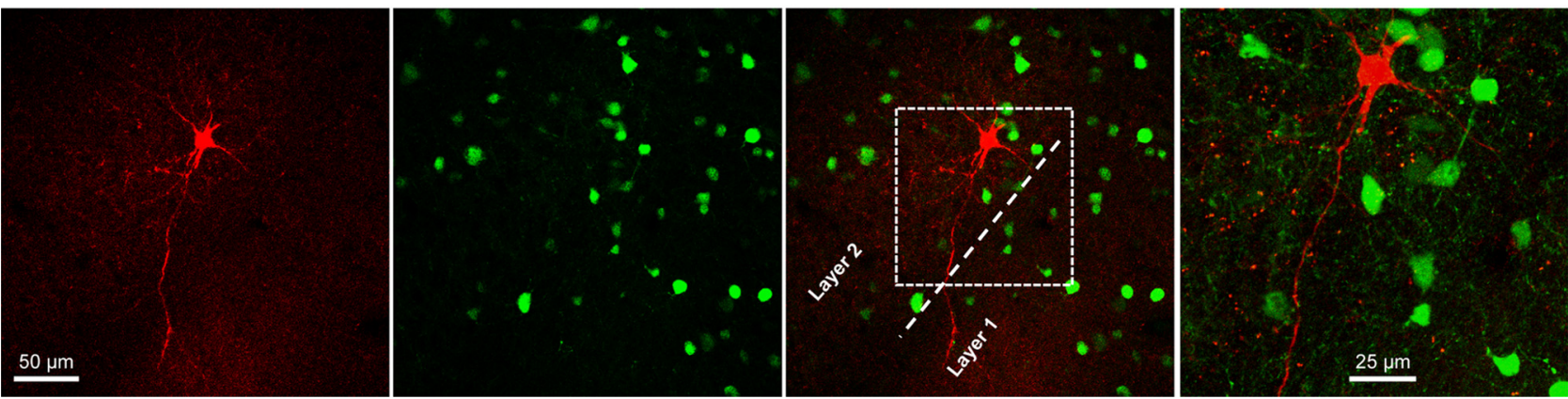

Figure 1. Single-cell recordings of odorant-evoked responses in the aPCX of head-restrained awake mice. $\boldsymbol{A}$, Schematic representation of the methods for recordings and stimulus delivery. The mouse head was restrained by a head plate, and the animal was able to maneuver on the top surface of an air-supported floating Styrofoam ball. The frictionless movement of the floating ball reduces possible head torques and provides sufficient stability for single-cell recordings from the aPCX. A glass pipette filled with 4\% Neurobiotin was lowered through a cranial window for electrophysiological recording and juxtacellular labeling. Odorants were stored in headspace vials on a panel and delivered with a robotic olfactometer. For control, we used purified room air of the same flow rate from one headspace vial in the panel. $\boldsymbol{B}-\boldsymbol{E}$, Physiological and morphological properties of a typical pyramidal neuron in the aPCX of a head-restrained awake mouse. $\boldsymbol{B}, \boldsymbol{C}$, Confirmation of single-cell recording by spike sorting analysis $(\boldsymbol{B})$ and spike train autocorrelogram $(\boldsymbol{C})$. The two panels in $\boldsymbol{C}$ illustrate the autocorrelograms at two different time scales. Arrows point to the autocorrelation peaks likely generated by respiratory rhythms. $\boldsymbol{D}$, Sample physiological traces show odorant-evoked responses for the same cell in $\boldsymbol{B}$ and $\boldsymbol{C}$. Benzaldehyde (left) and toluene (middle) but not control air (right) reliably evoked clear excitatory responses when the stimuli were applied for four consecutive trials. Bottom panels show the mean PSTH plots of spike firing for each stimulus. Horizontal bars indicate $2 \mathrm{~s}$ odorant presentations in this and following figures. $\boldsymbol{E}$, Cell-type verification by morphology and neurotransmitter phenotype. Juxtacellular labeling revealed that the recorded cell shown in $\boldsymbol{B}-\mathbf{D}$ was most likely a layer 2 pyramidal neuron in the aPCX. This cell (red) exhibited dendritic morphology typical of pyramidal neurons in the aPCX. In addition, it lacked GFP expression (green), which serves as a marker of GABAergic neurons in GAD67-GFP mice. The right shows the magnified view of the area defined by the dashed box at its left.

of the aPCX. These results suggest that olfactory information is represented by functionally heterogeneous populations of pyramidal neurons and contribute to our understanding of the roles of intracortical circuitry in olfactory processing.

\section{Materials and Methods}

Animals and surgery. Animal care and use conformed to institutional guidelines of the National Institute of Biological Sciences (Beijing, China). All experiments were performed on adult heterozygous gluta- 
mate decarboxylase (GAD) 67-green fluorescent protein (GFP) $(\Delta$ neo) mice $(22$ males and 4 females). In these mice, GFP is selectively expressed under the control of the endogenous GAD67 gene promotor, resulting in GFP expression selectively in GABAergic neurons (Tamamaki et al., 2003). These knock-in mice were named as GAD67-GFP mice for simplicity. These mice are viable with no apparent changes in survival, gross brain structure, or behavior (Tamamaki et al., 2003).

The method of physiological recordings from head-restrained awake mice was based on the techniques developed for imaging neuronal activities from head-restrained, mobile mice on a spherical treadmill (Dombeck et al., 2007). Briefly, for head-plate implantation, mice were anesthetized by intraperitoneal injection of atropine $(0.05 \mathrm{mg} / \mathrm{kg})$ and pentobarbital $(80 \mathrm{mg} / \mathrm{kg})$. A mouse was then mounted in a stereotaxic holder and kept warm $\left(37^{\circ} \mathrm{C}\right)$ with an electric heating pad (BrainKing Biotech). A custom-made head plate with a $4-\mathrm{mm}$ diameter hole was placed on the skull, and the hole was centered over the aPCX. The head plate was then affixed to the skull with stainless steel 000-120 machine screws and dental cement. The exposed skull in the $4 \mathrm{~mm}$ hole was thinned but not broken. Mice were allowed to recover for $3-5 \mathrm{~d}$ before recording. On the day of recording, a mouse was head fixed and allowed to learn to balance and walk on the spherical treadmill for 2-3 h. Odor pulses were also sequentially presented for two to three trials during this period. The training appeared to be sufficient for animals to adjust to the headfixed condition and the paradigm of odorant application, because they stayed quiet most of time and walked occasionally. Mice were delivered with water drops once per hour, and an entire recording session typically lasted $4 \mathrm{~h}$.

Electrophysiological recordings. Immediately before recordings, a small hole $(200-300 \mu \mathrm{m})$ was quickly opened in the skull for lowering electrodes toward the aPCX. Borosilicate microelectrodes (impedance, 20-30 M $\Omega$ ) were pulled on a Sutter horizontal puller (P-97; Sutter Instrument). The electrodes were backfilled with $4 \%$ Neurobiotin (Vector Laboratories) dissolved in $1 \mathrm{M} \mathrm{NaCl}$. We began to search for extracellular single units when the tip of the recording pipette reached $\sim 3 \mathrm{~mm}$ below the pial surface. After the isolation of a single unit, electrophysiological signals were amplified $10 \times$

by an AxonClamp 2B amplifier (Molecular Devices), band-passed filtered at $0.5-3 \mathrm{kHz}$, and further amplified $10 \times$ (model 440; Brownlee Precision), and digitized at $15 \mathrm{kHz}$ by a E-series DAQ card (National Instruments). Data acquisition and experimental control were implemented by custom-written software using driver programs provided by National Instruments.

Odor delivery. Odor stimuli consisted of 24 monomolecular chemical compounds: ethanol, cyclohexanol, 2-decanol, 3-methylbutanol, ethyl acetate, ethyl butyrate, 2-phenethyl acetate, $\mathrm{N}$-amyl-acetate, 2-methylbutyraldehyde, heptanal, citral, benzaldehyde, isophorone, geranyl acetone, 1-pentanol, 2-pentanone, benzene, toluene, styrene, benzyl ether, 2,5dimethylpyrazine, 2'-hydroxyacetophenone, propiophenone, and acetophenone. The functional groups of the odorants include alcohol, acetate, aldehyde, ketone, benzene, ether, pyrazine, and aromatic ring. All odorants were stored in headspace vials, and their saturated vapor plus one air control were delivered by a multichannel robotic olfactom- eter (I\&J7200C; Fisnar) at the flow rate of $40 \mathrm{ml} / \mathrm{min}$ (Fig. 1 A). Odorant vapor was injected into a constant air stream with the flow rate of $4 \mathrm{~L} / \mathrm{min}$ in front of the mouse nostrils, resulting in a $1 \%$ dilution of saturated vapor. Each odorant was presented for four consecutive trials, and the sequence of delivering 24 odorants plus air control was identical for all cells. For each trial, the duration of odorant pulse was $2 \mathrm{~s}$ with an intertrial interval of $20 \mathrm{~s}$ to reduce habituation (Wilson, 1998). To ensure accuracy in the timing of stimulus delivery, odorants were diverted into the vacuum for the first $1 \mathrm{~s}$ and then switched to the mouse nostrils with a three-way final valve (WTB-3R-M6F; Takasago Electric). To minimize residual odorants from previous trials, an additional stream $(100 \mathrm{ml} / \mathrm{min})$ of purified air was injected into the final valve $3 \mathrm{~s}$ after odorant presentation. Surrounding air was cleared by a vacuum system, and Teflon tubing was used to further reduce cross-contamination. 
A
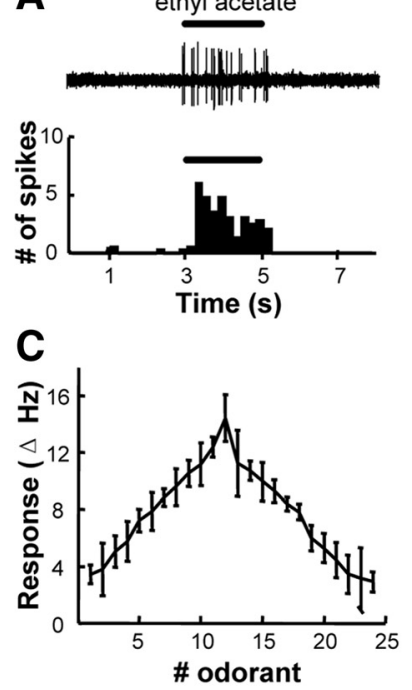

D

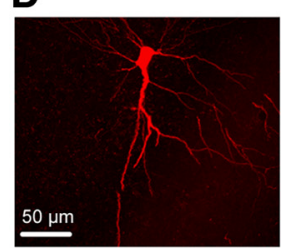

B

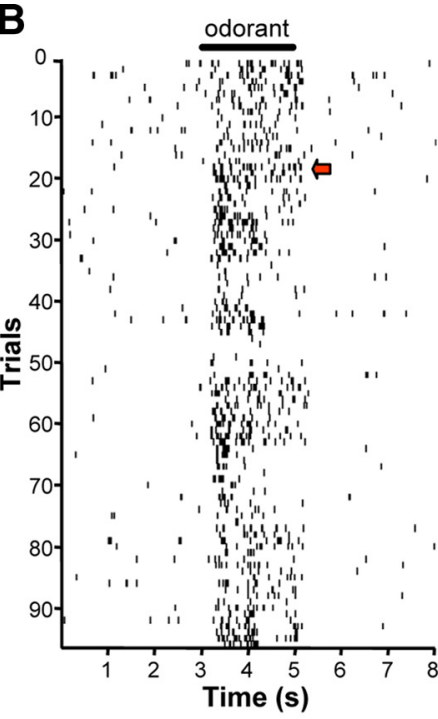

$\mathbf{E}$

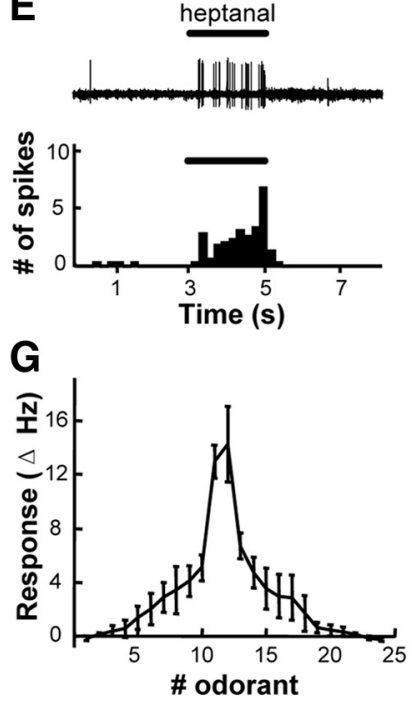

F

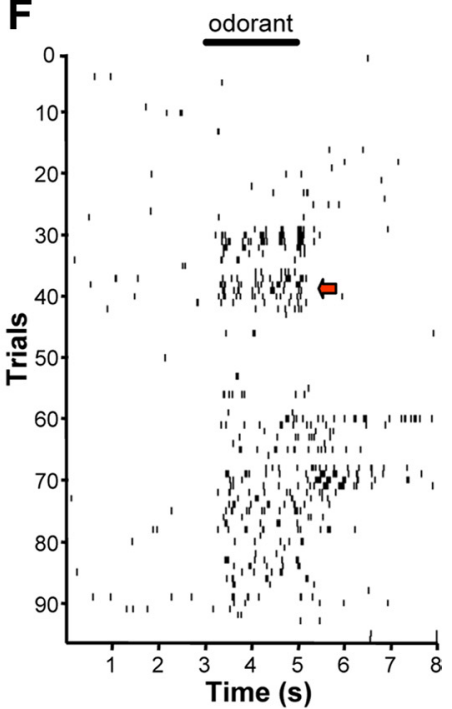

H
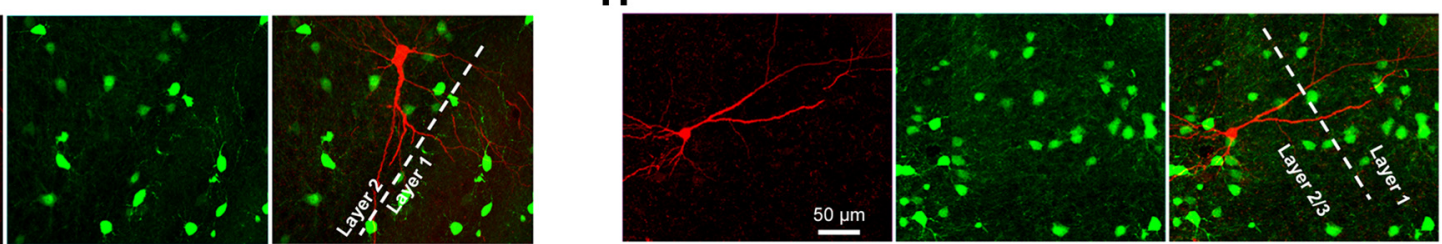

Figure 3. Two representative type I PNs. A-D, One PN was excited by a majority of test odorants. $A$, Physiological trace (top) and averaged PSTH (bottom) illustrate the excitatory response of the cell to $1 \%$ ethyl acetate. $\boldsymbol{B}$, Raster plot of a total of 96 trials of odorant application. Trials were aligned along the vertical axis. Each odorant was applied consecutively for four trials, and a total of 24 odorants were tested. Action potentials in each trial are plotted as black dots along the horizontal axis. Red arrow points to the responses to ethyl acetate as shown in $\boldsymbol{A}$. The sequence of odor application was identical for all cells. C, Broad tuning curve of the cell. Numbers represent changes of firing rates $(\Delta \mathrm{Hz}$ ) induced by odorant application, with positive ones indicating excitation and negative ones inhibition. To plot tuning curves in this and following figures, the response strengths of individual cells are arranged against all odorants along the horizontal axis. The strongest excitatory responses are located in the middle of the curve and weak or inhibitory responses at both ends. Error bars indicate SEM in this and the following figures. $\boldsymbol{D}$, The morphology of the PN. The recorded neuron (red) extended its apical dendrites into the layer 1 and basal dendrites into the layer 3 of the aPCX. Lack of GFP expression (green) indicates that the labeled cell is non-GABAergic. $\boldsymbol{E}-\boldsymbol{H}$, Another PN was also excited by many odorants, although its responses appeared to be more selective than the cell shown in $\boldsymbol{A}-\boldsymbol{D}$. Same conventions as in $\boldsymbol{A}-\boldsymbol{D}$.

Data analysis. Data analysis was performed with a combination of custom-written programs in Matlab (MathWorks) and Spike2 software (Cambridge Electronic Design). Action potentials were sorted using Spike2 Software (Fig. 1 B). Single-unit recordings were verified by a clear refractory period within the autocorrelograms of recorded spiking trains (Fig. 1C). Peristimulus time histograms (PSTHs) were computed by counting the number of action potentials within sequential time bins $(200 \mathrm{~ms})$ and then averaged over four trials for each odorant.

The response strength of an individual neuron to an odorant was calculated by subtracting its baseline firing rate during $3 \mathrm{~s}$ before stimulus presentation from the firing rate during the $2 \mathrm{~s}$ odorant application. An excitatory response was considered significant if the elevation in firing rate during the odor presentation exceeded 2 SDs of spontaneous firing rates. Because most of PNs exhibit low basal firing rates, the value of inhibitory response strength was small in terms of absolute change of firing rates. However, in these cases, the inhibitory odorants produced clear suppression of action potential firing. Using a previously reported criterion (Kreher et al., 2008), we considered an inhibitory response significant if the decline in firing rate during the $2 \mathrm{~s}$ odor presentation was at least 1 spike/s and also exceeded the value of $50 \%$ baseline firing rate. To plot response profiles, the response strength of an individual neuron to a specific odorant was color coded, with excitation (range, $0-20$ spikes/s) shown in red and inhibition ( $0-100 \%$ suppression from basal rate) shown in blue.

The classification of cell types was based on soma location, dendritic morphology, neurotransmitter phenotypes, and response profiles. Only cells with soma located in the aPCX were analyzed and presented. Because cells were recorded from GAD67-GPF mice, a cell was considered GABAergic if GFP was expressed in its soma. A cell was classified as a PN if it lacked GFP expression, its soma was located in the layers $2 / 3$ of the aPCX, and it extended apical dendrites into the layer 1 and basal dendrites into the layer 3 (Neville and Haberly, 2004). PNs were further divided into functional subtypes by their response profiles. Type I PNs exhibited predominantly excitatory responses (excited by $>20 \%$ of odorants). These cells were rarely inhibited by odorants. Type II PNs showed broad inhibitory responses (inhibited by $>20 \%$ of odorants). Type III PNs showed highly selective responses (excited or inhibited by $<20 \%$ of odorants) or were nonresponsive to test odorants.

Histology. After recordings, neurons were labeled using the juxtacellular labeling technique (Pinault, 1996). Briefly, Neurobiotin in a recording pipette was electrophoresed into neurons with small positive currents (2-7 nA, $0.2 \mathrm{~s}$ on/0.2 s off). One hour after the completion of labeling, mice were killed with an overdose of pentobarbital and then perfused with saline and $4 \%$ paraformaldehyde in PBS with $0.2 \%$ picric acid. The brains were postfixed in $4 \%$ paraformaldehyde overnight at $4^{\circ} \mathrm{C}$ and cryoprotected with $30 \%$ sucrose. Coronal sections $(40-50 \mu \mathrm{m})$ were cut with a freezing cryostat (Leica CR 1900) and then reacted with cyanine 3 (Cy3)-streptavidin (1:500, Jackson ImmunoResearch) overnight at $4^{\circ} \mathrm{C}$. Images of fluorescently labeled cells were acquired by a confocal microscope (Carl Zeiss LSM 510 Meta) using a $40 \times$ oil-immersion objective and processed by Adobe Photoshop.

\section{Results}

\section{Recording and labeling single aPCX neurons from} awake mice

To achieve efficient recording and labeling of single cells from the aPCX of awake mice, we adopted a recently reported method of 
imaging or recording neuronal activity from head-restrained awake, mobile mice (Dombeck et al., 2007; Niell and Stryker, 2010). To facilitate the identification of neurotransmitter phenotypes, we used GFP expression in GAD67-GFP mice as a marker of GABAergic neurons (Tamamaki et al., 2003). A custom-made stainless steel head plate was first implanted over the head of an adult mouse. After a few days of recovery, the mouse was head fixed by tightening the head plate to two stainless steel cross bars and was then allowed to move on an air-supported, frictionless spherical treadmill (Fig. $1 A$ ). To test the odorant selectivity of aPCX neurons, we used 24 structurally dissimilar monomolecular odorants, which cover a broad range of functional groups, including alcohol, acetate, aldehyde, ketone, aromatic, and ether. A putative mouse pheromone, 2,5-dimethyl pyrazine, was also included. Odorants were stored in headspace vials, and their $1 \%$ dilution of saturated vapor was delivered by a robotic olfactometer.

The firing activity of neurons in the aPCX was recorded extracellularly by using glass pipettes. Individual recordings were verified to be from single neurons by similar spike shapes and amplitudes across the recording session of $\sim 1 \mathrm{~h}$ (Fig. $1 B$ ) and a clear refractory period in the autocorrelograms of spike trains (Fig. $1 C)$. We commonly observed peaks within the range of 200-300 ms in spike autocorrelograms, suggesting firing activities coupled to respiratory cycles (Fig. $1 C)$. Figure $1 D$ shows the typical pattern of odorant-elicited firing of action potentials from one representative cell in the aPCX, which was strongly activated by $1 \%$ benzaldehyde and toluene. At $\sim 300 \mathrm{~ms}$ after the opening of final solenoid valve, vigorous firing of action potentials were evoked during the entire period of odorant application (2 s). The spike firing was rhythmic at $4-5 \mathrm{~Hz}$, suggesting activity coupled to respiratory cycles (Wilson, 1998; Litaudon et al., 2003; Rennaker et al., 2007). Moreover, the responses were reliable across multiple consecutive trials when the same odorant was presented (Fig. 1D). Control air with the same flow rate did not produce any obvious response (Fig. $1 D$, right), demonstrating that the responses were produced by odorants rather than the change of flow rate.

After recordings, cells were labeled by juxtacellular electrophoresis of Neurobiotin and visualized with Cy3-streptavidin. We identified neuron types by cell soma location, dendritic morphology, and neurotransmitter phenotypes as revealed by GFP expression in the GAD67-GFP mice. Like the hippocampus, the PCX is a three-layered paleocortex. The somata of PNs are located in the layers $2 / 3$, and their apical dendrites form synapses with the axons of mitral/tufted cell in the layer 1 of the PCX (Neville and Haberly, 2004). PNs are glutamatergic and nonGABAergic. The somata of nonpyramidal neurons ( $\mathrm{nPNs}$ ) are distributed in all three layers, and many of nPNs are GABAer-
B

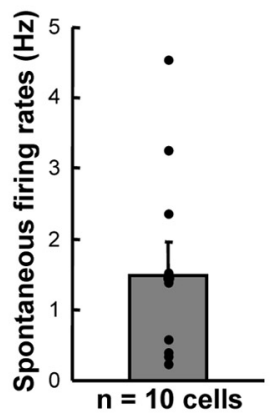

C

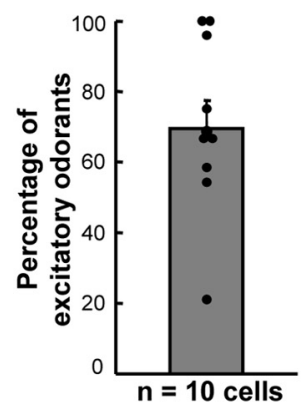

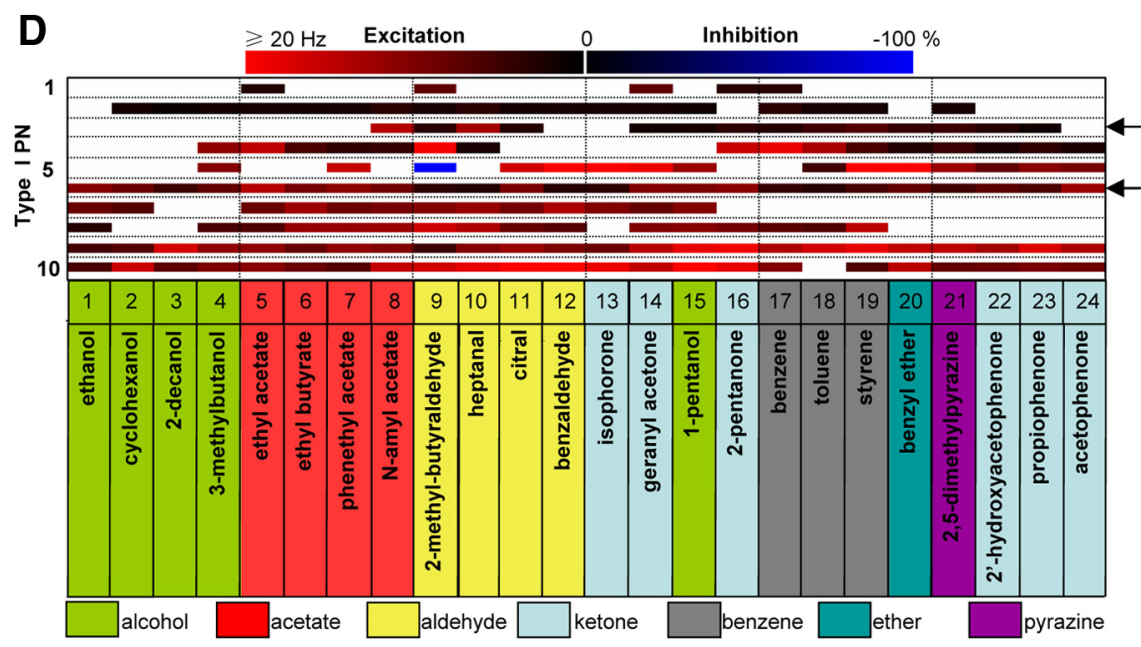

Figure 4. Group data for the 10 type I PNs, showing their broad excitatory responses to test odorants. A, Composite drawings of two coronal sections illustrating the distribution pattern of type I PNs (red dots) in the layers $2 / 3$ of the aPCX. Cells were recorded fresponse profiles for the type I PNs. The two arrows point to the cells shown in Figure 3. Red color indicates a range of [0 20] of sil second for excitatory responses, and blue indicates a range of [0 100\%] reduction from basal firing rate for inhibitory . Odorant identities and their respective odor numbers are shown below the horizontal axis. The odor numbers represent the sequence of odor application during tests and apply to the following figures. Color indicates at least one of the functional groups for the odorants, although some odorants have multiple functional groups.

gic. A non-GABAergic cell in layer 3 was considered nonpyramidal if it did not extend its dendrites into the layer 1. Figure $1 E$ shows the morphology of the cell described in Figure $1 B-D$. The soma of this cell was located in the layer 2 of the aPCX. It extended apical dendrites to the layer 1 and basal dendrites to the layer 3. Lack of GFP expression indicates that this cell was not GABAergic. Based on these features, we classified this cell as a PN.

Thus, our methods allow stable single-cell recordings of olfactory responses as well as labeling of cell morphology from the aPCX of awake mice.

\section{Overall selectivity pattern of aPCX neurons}

We recorded and labeled a total of 57 aPCX cells, including 40 PNs, 11 non-GABAergic nPNs, and 6 GABAergic cells. Each cell was tested with 24 odorants, producing a total of 1368 odor-cell pairs. Among them, 20.8\% (284 odor-cell pairs) were significant excitatory responses and $15.8 \%$ (216 pairs) were clear inhibitory responses. These ratios are primarily consistent with what have been observed from anesthetized or behaving animals using either electrophysiological recordings or optical imaging of calcium signals (McCollum et al., 1991; Schoenbaum and Eichenbaum, 1995; Rennaker et al., 2007; Poo and Isaacson, 2009; Stettler and Axel, 2009; Isaacson, 2010). 
A

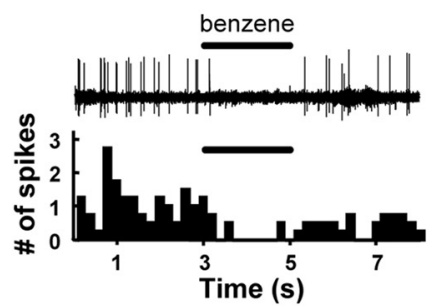

C

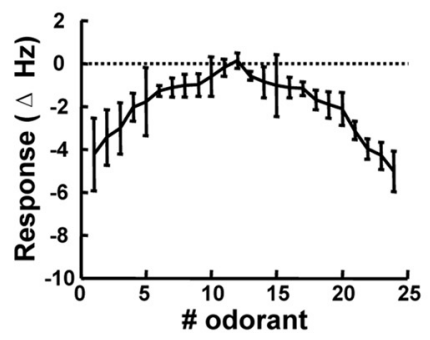

D

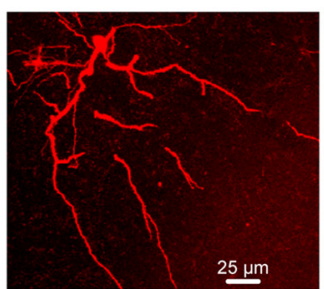

$\mathbf{E}$
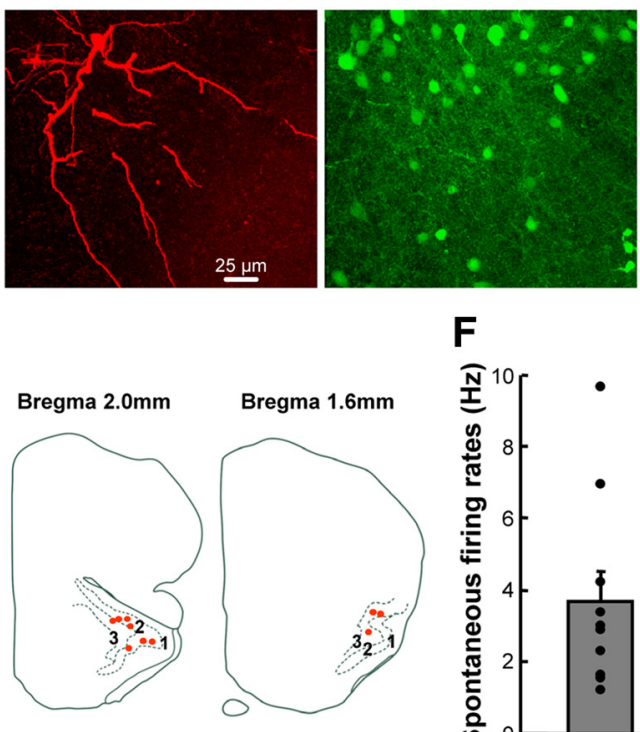

$\mathbf{F}$

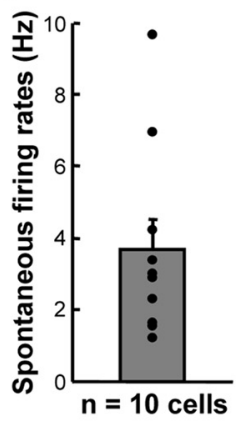

G
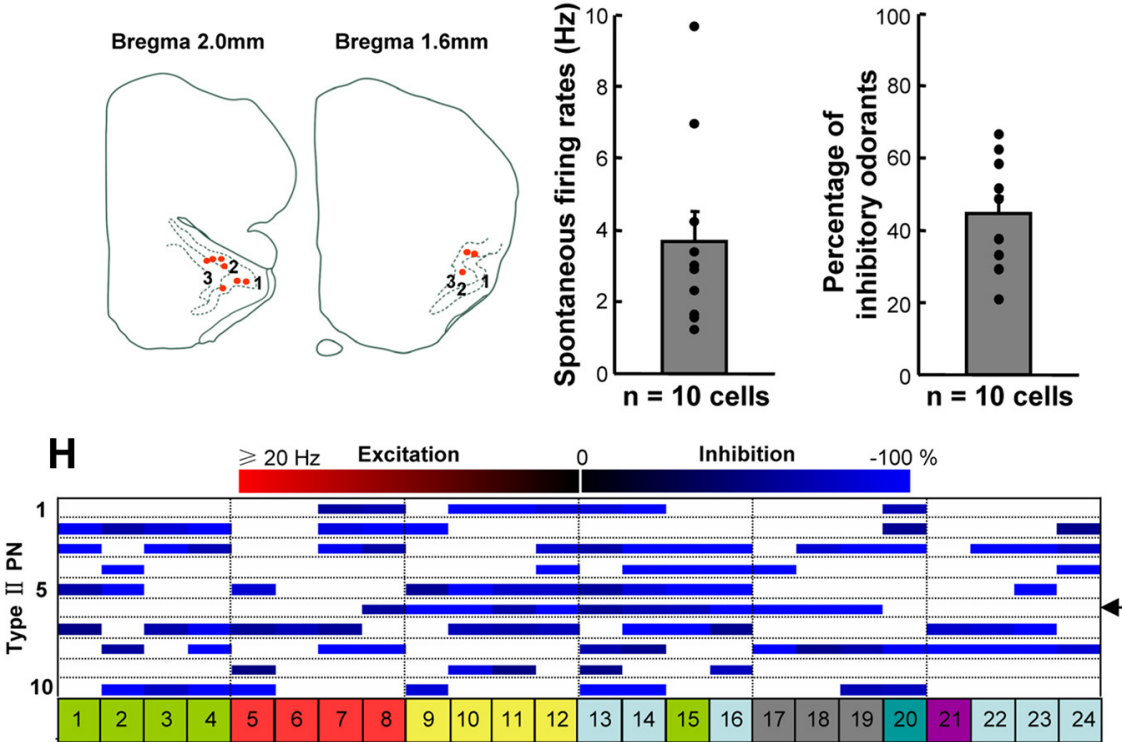

Figure 5. Type II PNs are broadly inhibited by odorants. $\boldsymbol{A}-\mathbf{D} \boldsymbol{D}, 0$ ne representative type II PN. $\boldsymbol{A}$, Raw physiological trace and mean PSTH show strong inhibition of the cell by $1 \%$ benzene. $B$, Raster plot of the spiking responses to 24 test odorants, each of which was presented for four consecutive trials. Blue arrow points to plots for benzene as shown in $A$. C, Inhibitory tuning curve of the PN shown in $\boldsymbol{A}$ and $\boldsymbol{B}$. D. Dendritic morphology and the lack of GFP expression suggest that this cell is most likely a PN. $E$, Composite drawings of two coronal sections showing the soma location of type II PNs (red dots) in the layers $2 / 3$ of the aPCX. F, Spontaneous firing rates of type II PNs. G, The percentage of inhibitory odorants for the 10 type II PNs. $\boldsymbol{H}$, Plot of response profiles for all type II PNs. Arrow at right points to the cell shown in $\boldsymbol{A}-\boldsymbol{D}$. Same conventions as in Figure $4 D$.

However, the two ratios were highly variable across distinct cell types. For the $40 \mathrm{PNs}$, the overall excitatory and inhibitory ratios were 19.7 and $12.6 \%$, respectively. Whereas these resemble the overall ratios observed from the entire dataset of recorded cells, the two ratios varied dramatically across individual PNs, leading us to further divide PNs into three functional subtypes based on the response profile of individual neurons (Fig. 2). One- quarter of PNs ( $n=10$ cells) were broadly excited but rarely inhibited by odorants, resulting in the excitatory and inhibitory ratios of 69.6 and $0.4 \%$, respectively. For simplicity, we defined these neurons as type I PNs. Another one-quarter of PNs ( $n=10$ cells; type II PNs) exhibited no excitation but clear inhibition to almost half of odorants (excitatory vs inhibitory ratios, 0 vs $44.6 \%$ ). For the rest of $20 \mathrm{PNs}$ (type III PNs), we observed very selective responses in terms of either activation or inhibition (excitatory vs inhibitory ratios, 4.6 vs $2.7 \%$ ). Nonpyramidal neurons also exhibited very different response profiles according to their neurotransmitter phenotypes. Non-GABAergic nPNs were typically inhibited by odorants (excitatory vs inhibitory ratios, 12.1 vs $35.2 \%$ ). In contrast, GABAergic neurons displayed broadly excitatory responses to odorants (excitatory vs inhibitory ratios, 43.8 vs $1.4 \%)$

These results therefore indicate rich functional heterogeneity in the aPCX, suggesting different roles of distinct cell types in signal processing and odor representation. Next we will describe the response properties of each cell type in more details.

PNs exhibit diverse selectivity profiles

Figure 3 shows two examples of type I PNs that were nonselectively excited by a diverse array of structurally dissimilar odorants. For the cell shown in Figure $3 A-D$, it was quiet in the basal state but responded with vigorous firing of action potentials in the presence of ethyl acetate (Fig. 3A). Raster plot of spike trains across all 96 test trials demonstrates that the increase in firing frequency was tightly coupled to odorant application (Fig. 3B). All 24 test odorants produced significantly excitatory responses and strong excitation ( $>10$ spikes/s) was observed for several odorant stimuli, resulting in a broad tuning curve (Fig. $3 C)$. Juxtacellular labeling revealed that this non-GABAergic cell extended its apical dendrites into the layer 1 of the aPCX, suggesting that it was a PN (Fig. $3 D)$. Some type I PNs exhibited a narrower tuning. For example, the cell shown in Figure $3 E-H$ was significantly excited by 14 odorants covering all seven functional groups, with two of the odorants producing strong excitation.

The somata of all type I PNs $(n=10)$ were located in the layers $2 / 3$ of the aPCX (Fig. $4 A$ ). These cells tended to remain inactive in the basal state, with an average spontaneous firing rate of $1.5 \pm$ $0.5 \mathrm{spike} / \mathrm{s}$ (range, $0.2-4.5 \mathrm{spikes} / \mathrm{s}$ ) (Fig. 4B). All type I PNs were excited by $>20 \%$ of odorants (at least 5 of 24 test odorants), with 
three cells being excited by virtually the entire set of odorant stimuli (Fig. $4 C, D$ ). Moreover, most of them ( $n=8$ of 10 cells) responded strongly ( $>10$ spikes/s) to at least one odorant (Fig. 4D). In contrast to the average high likelihood of exciting a type I PN by an odorant ( 70\%) (Fig. $4 C)$, clear inhibitory response was observed for only 1 of 240 odor-cell pairs (Fig. 4D). More importantly, none of the type I PNs displayed any apparent preference of the chemical functional groups of odorant molecules. The effective stimuli of individual type I PNs generally belonged to different functional groups (Fig. 4D).

In drastic contrast to type I PNs, type II PNs showed predominantly inhibitory responses to odorants ( $n=10$ cells). Their spontaneous firing of action potentials could be substantially suppressed during odorant application (Fig. 5A,B). The tuning curve of inhibitory responses was usually broad, suggesting lack of selectivity for inhibition (Fig. 5C). These cells extended apical dendrites to the layer 1 and basal dendrites to layers $2 / 3$. They did not express GFP, suggesting that they were non-GABAergic (Fig. 5D). In addition, their somata were distributed in the layers $2 / 3$ (Fig. 5E), further suggesting that they were pyramidal neurons. Compared with type I PNs, type II PNs displayed slightly higher spontaneous firing rates (mean, $3.7 \pm 0.9 \mathrm{~Hz}$ ) (Fig. 5F). All type II PNs were inhibited by at least $20 \%$ of odorants tested (Fig. 5G), whereas no excitatory responses were produced by any odorant tested. In addition, strong inhibition (100\% suppression of firing) can be observed in all 10 cells (Figs. 2, 5H). Resembling the excitatory responses of type I PNs, the inhibitory responses of individual type II PNs did not show any selectivity of functional groups (Fig. $5 \mathrm{H}$ ). For example, the cell shown in Figure $5 A-D$ was inhibited by 12 test odorants, covering five functional groups: acetate, aldehyde, ketone, alcohol, and aromatic (Fig. 5H).

One-half of recorded PNs were classified as type III PNs ( $n=20$ of 40 cells). These cells either responded selectively or exhibited no obvious response to the 24 test odorants. One example is shown in Figure $6 A-D$. Benzyl ether (1\%) evoked a weak excitatory response from this cell, and the other 23 odorant stimuli were ineffective (Fig. 6A-C). Its dendritic morphology, soma location, and lack of GFP expression strongly suggested that it was a PN (Fig. 6D). The somata of all type III PNs were located in the layers $2 / 3$ of the aPCX (Fig. $6 E$ ). Their spontaneous firing rates were low (mean, $0.62 \pm 0.2$ spikes/s) (Fig. 6 F). Among these 20 cells, 11

A

C

D

E to the cell shown in $\boldsymbol{A}-\boldsymbol{D}$.
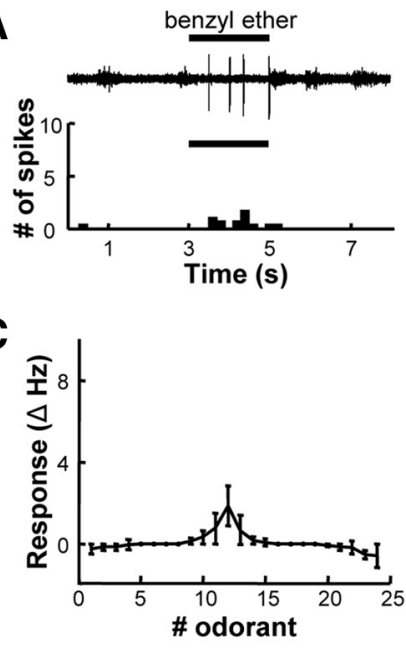

B
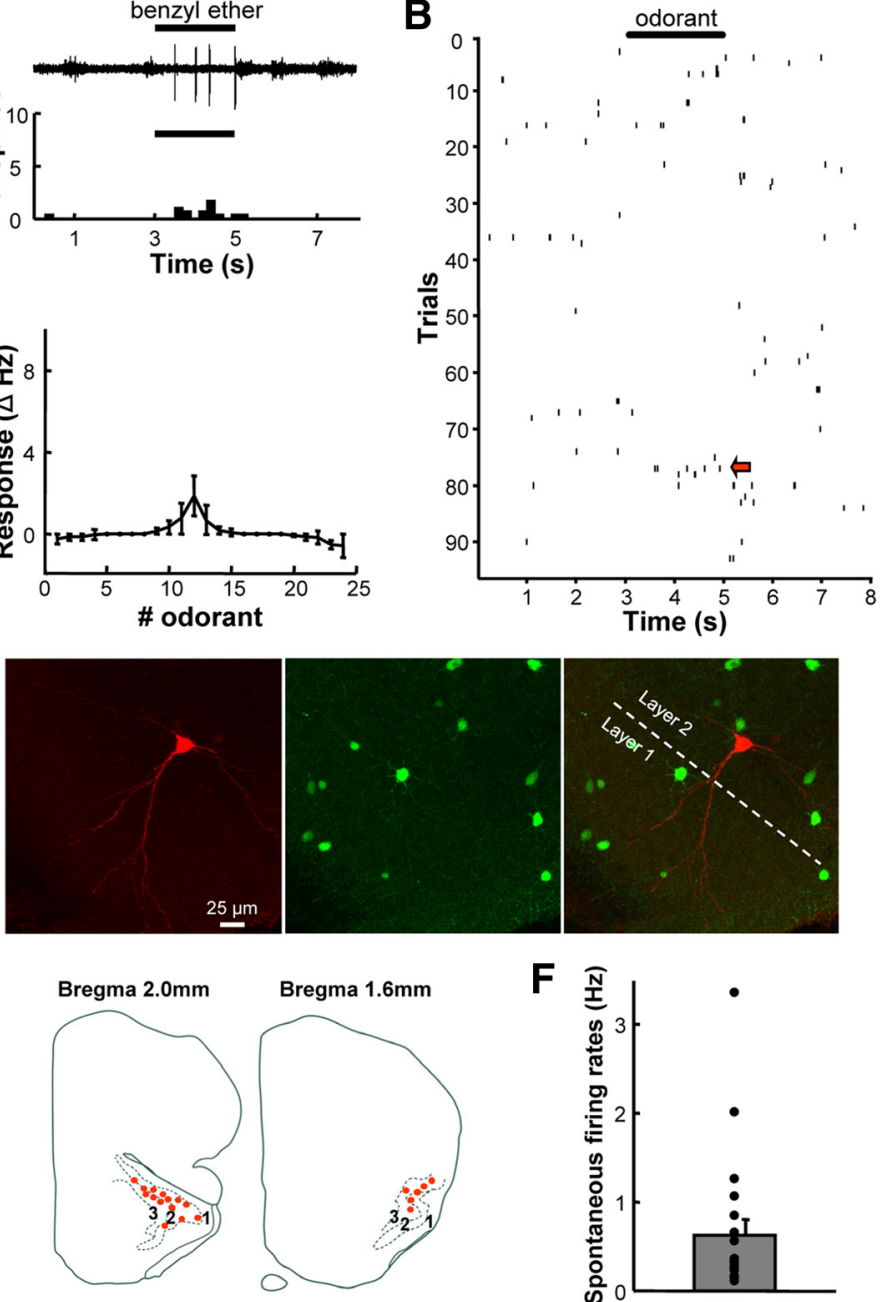

$\mathbf{F}$
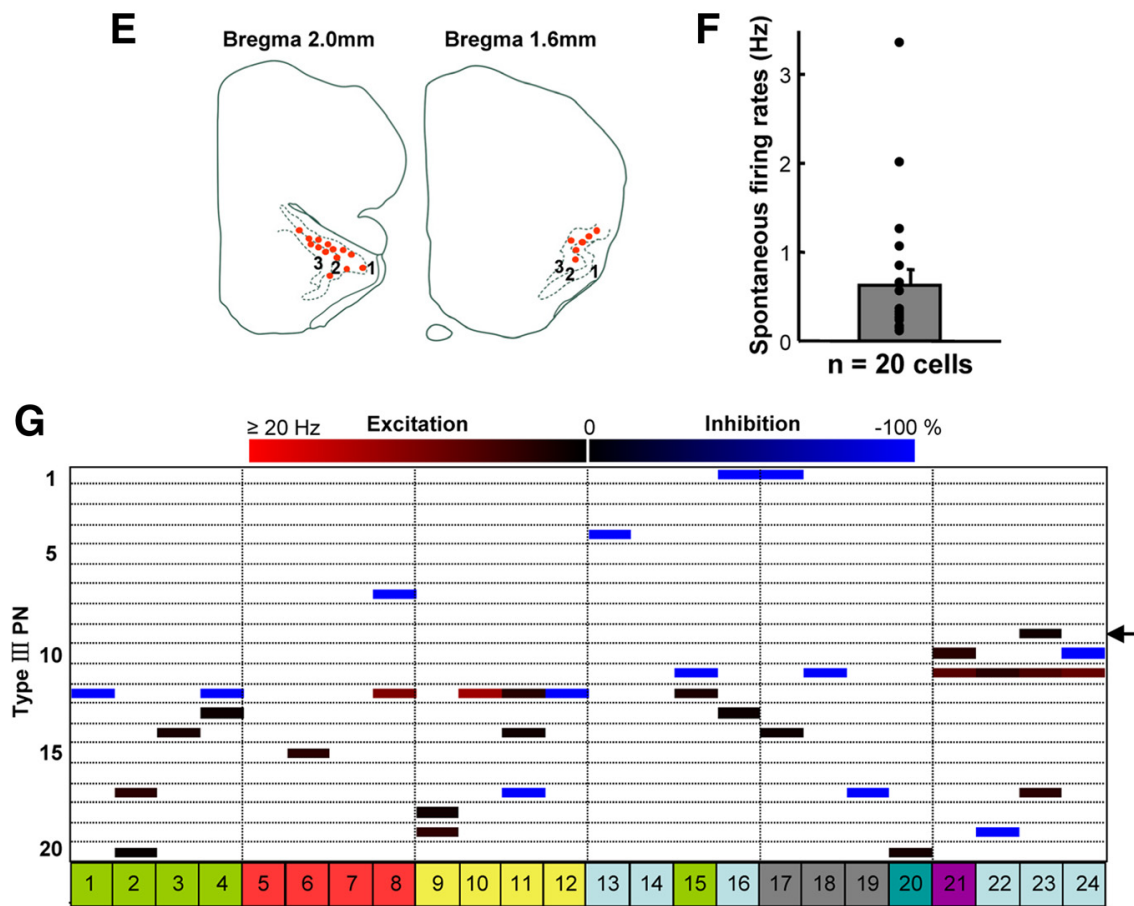

Figure 6. Type III PNs respond selectively to test odorants or lack responses to any odorant stimulus. $\boldsymbol{A}-\boldsymbol{D}, 0$ ne representative type III PN. $\boldsymbol{A}$, Raw physiological trace and mean PSTH show weak excitation of the cell by $1 \%$ benzyl ether. $\boldsymbol{B}$, Raster plot of spiking response of the cell to 24 odorants. The red arrow points to plots for benzyl ether. $\boldsymbol{C}, 0$ lfactory tuning curve. $\boldsymbol{D}$, The morphology of the type III PN. $\boldsymbol{E}$, Composite drawings of two coronal sections show the soma location of type III PNs (red dots) in the layers $2 / 3$ of the aPCX. F, Spontaneous firing rates of type III PNs. G, Plot of response profiles for the 20 type III PNs, showing selective responses of 14 cells and the lack of significant responses for six cells. Arrow at right points 
A

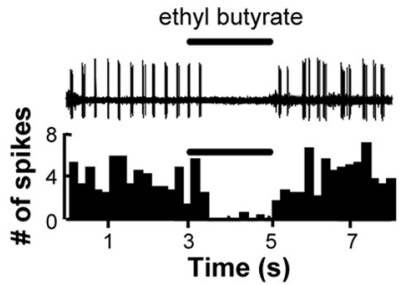

C

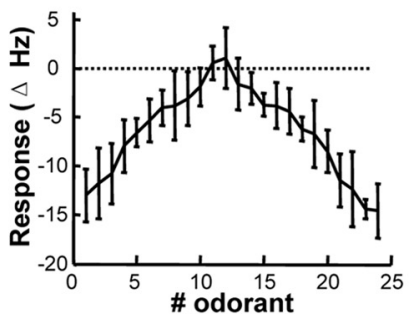

D
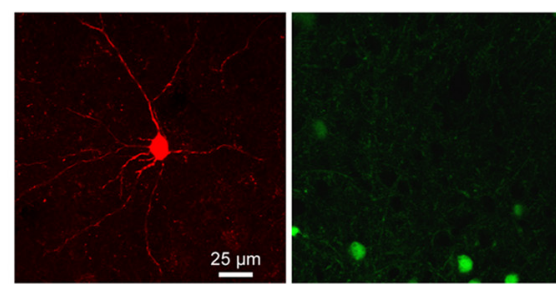

E

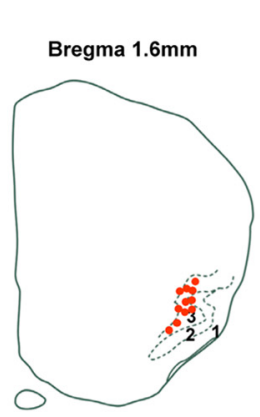

$\mathbf{F}$

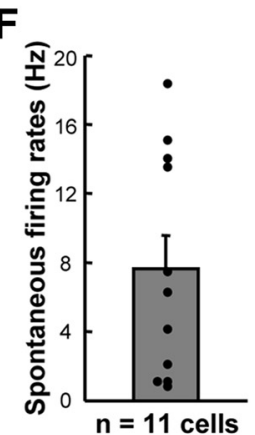

G
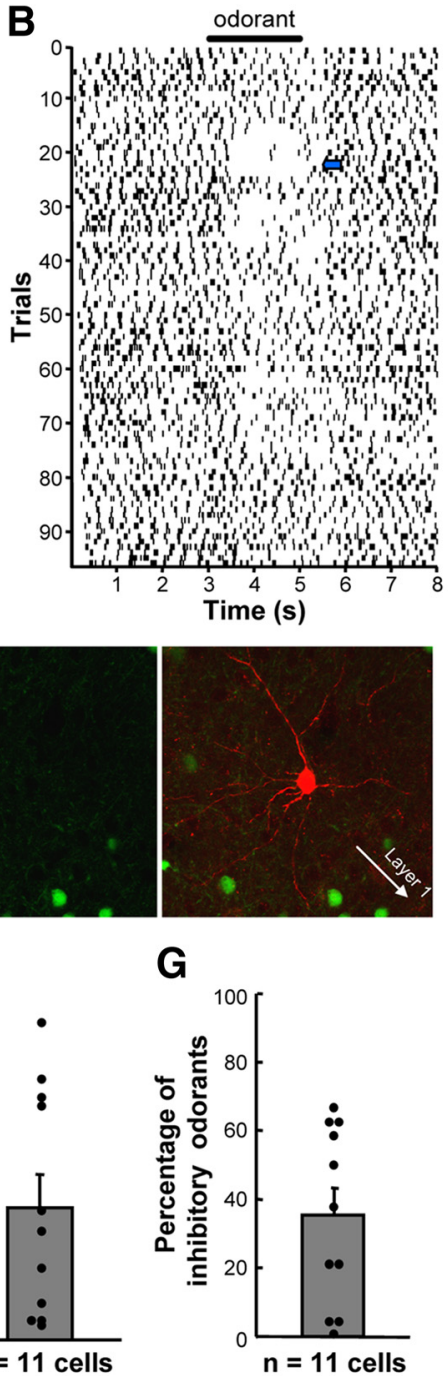

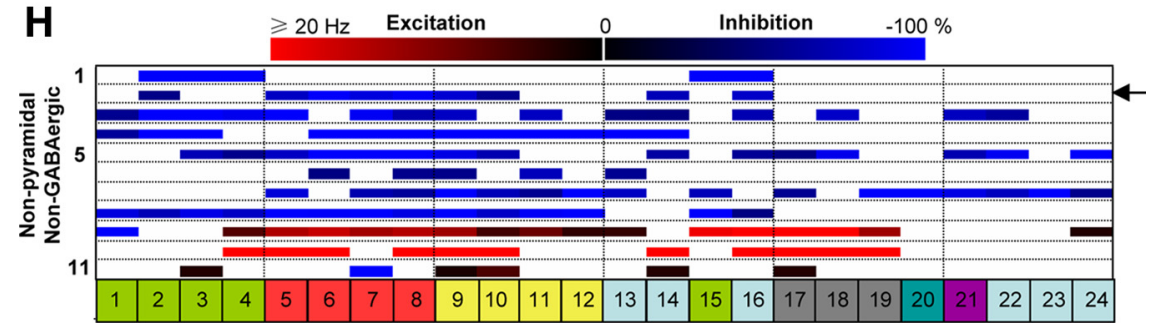

Figure 7. Layer 3 non-GABAergic nPNs exhibit high spontaneous firing rates and are broadly inhibited by odorants. $A-D, A$ typical non-GABAergic nPN. $\boldsymbol{A}$, Raw physiological trace and PSTH show strong inhibitory response of the cell to $1 \%$ ethyl butyrate. $\boldsymbol{B}, \boldsymbol{C}$, Raster plot $(\boldsymbol{B})$ and tuning curve $(\boldsymbol{C})$ of the $\mathrm{nPN}$ shown in $\boldsymbol{A}$. The blue arrow in $\boldsymbol{B}$ points to the responses to ethyl butyrate. $\boldsymbol{D}$, The morphology of the labeled cell. The soma of the recorded neuron was located in the layer 3 . It exhibited a multipolar dendritic morphology, but none of its dendrites reached the layer 1. The lack of GFP expression indicates that it is a non-GABAergic neuron. Arrow points to the direction of the layer 1. $\boldsymbol{E}$, Composite drawing shows the location of non-GABAergic nPNs in the layer 3 of the aPCX. $\boldsymbol{F}$, Typically high spontaneous firing rates for this type of neurons. $\boldsymbol{G}$, High percentage of inhibitory odorants. $\boldsymbol{H}$, Plot of response profiles for the 11 non-GABAergic nPNs, showing predominantly inhibitory responses to test odorants. Arrow at right points to the cell shown in $\boldsymbol{A}-\boldsymbol{D}$.

Non-GABAergic nPNs are typically inhibited by odorants In addition to PNs, anatomical studies have revealed multiple types of nPNs that are morphologically distinguishable (Haberly, 1983; Protopapas and Bower, 2000; Ekstrand et al., 2001). As in other cortical areas, a substantial number of nPNs are GABAergic and inhibitory in the piriform cortex. A prominent exception is a population of multipolar cells mainly in the layer 3 (Shepherd et al., 2004). The response properties of different subtypes of nPNs remain essentially unknown.

We recorded 11 non-GABAergic $\mathrm{nPNs}$ from the aPCX. These cells differed from PNs in their spontaneous firing levels and dendritic morphology. One example of such cell is shown in Figure $7 A-D$. This cell exhibited high spontaneous firing activity and was strongly inhibited by the application of $1 \%$ ethyl butyrate (Fig. 7A). Raster plot and the tuning curve of inhibitory responses show that it was clearly inhibited by 9 of 24 test odorants covering four functional groups (Fig. $7 B, C$ ). These non-GABAergic nPNs were featured with several major dendrites, with none of them reaching the layer 1 (Fig. $7 D$ ). In addition, their somata were only located in the layer 3 (Fig. 7E). These morphological features thus strongly suggest that these cells should be classified as a separate class of non-GABAergic nPNs. The spontaneous firing rates of the nonGABAergic nPNs were significantly higher than those of PNs (mean, $7.6 \pm 2.0 \mathrm{~Hz}$; $p<0.001, t$ test between PNs and nonGABAergic nPNs) (Fig. 7F). A majority ( $n=8$ of 11 cells) of this population of nPNs were inhibited nonselectively by almost of half of the test odorants, although the rest of three cells were excited by several odorants (Fig. 7G,H).

GABAergic neurons are nonselectively activated by odorants

GABAergic interneurons consist of 20\% of total cortical neurons, although the response properties of identified GABAergic neurons remain unclear. We recorded six aPCX layer 3 neurons that were identified to be GABAergic. The response pattern of one representative GABAergic cell is shown in Figure $8 A-C$. Like other GABAergic cells, this cell was spontaneously active in firing action potentials (Fig. 8A,B). Application of 1\% 2-decanol strongly activated the cell, resulting in a response strength of $>10$ spikes/s (Fig. $8 \mathrm{~A}$ ). Raster plot and the tuning curve show that it was significantly excited by 16 odorants covering all seven functional groups (Fig. $8 B, C$ ). None of the 24 odorants produced any clear inhibition. Although in this case its dendritic morphology was not well labeled, its soma was located in the layer 3 and its expression of GFP was unambiguously detected (Fig. 8D), suggesting that it was GABAergic.

The somata of all six GABAergic neurons were located in the layer 3 of the aPCX (Fig. 8E). These GABAergic cells exhibited significantly higher spontaneous firing rates than $\mathrm{PNs}(11.7 \pm 4.4$ spikes/s; $p<0.001, t$ test between PNs and GABAergic cells) (Fig. $8 F)$. The overall likelihood of activating a GABAergic cell by an 
odorant was $\sim 50 \%$ (Fig. $8 G$ ). In contrast, clear odorant-evoked inhibition was rarely observed (only 2 of 144 odor-cell pairs). Five of the six cells were activated by multiple odorants without any obvious preference of the chemical functional groups of test odorants (Fig. $8 H$ ).

\section{Discussion}

In this study, we examined the olfactory response properties of individual neurons by extracellular recording and juxtacellular labeling in the aPCX of awake mice. Our results show that neurons of different morphology and neurotransmitter phenotypes exhibit highly variable tuning in terms of both excitatory and inhibitory responses. Moreover, similarly high variability is found among pyramidal neurons. These findings have several implications regarding the odor representation and signal processing in the olfactory cortex.

Odor representation by functionally heterogeneous population of cortical neurons

Previous studies have unmasked remarkably precise projection patterns from the olfactory epithelium to the olfactory bulb. In the epithelium, OSNs expressing a specific OR is randomly distributed in one of the four epithelial zones (Ressler et al., 1993). The axons of these OSNs then converge onto two stereotypically located glomeruli in the MOB, thus forming a spatial glomerular map (Ressler et al., 1994; Vassar et al., 1994; Mombaerts et al., 1996). A monomolecular odorant activates a discrete, sparse set of glomeruli (Rubin and Katz, 1999; Uchida et al., 2000; Wachowiak and Cohen, 2001; Soucy et al., 2009), suggesting that olfactory information is encoded by spatially organized glomerular modules. Consistently, mitral/tufted cells respond selectively to odorants that activate their presynaptic OSNs, with their tuning further sharpened by lateral inhibition (Yokoi et al., 1995; Mori et al., 1999; Tan et al., 2010). In contrast to the discrete spatial activation patterns in the bulb, individual odorants activate a unique ensemble of neurons that appear to be sparsely and randomly distributed across the piriform cortex (Illig and Haberly, 2003; Rennaker et al., 2007; Stettler and Axel, 2009).

It had been technically challenging to study how individual neurons of a specific cell type encode olfactory information in the aPCX of awake animals. Most of conclusions on the olfactory encoding in the piriform cortex had been derived from animals anesthetized with urethane or ketamine. Urethane results in different olfactory response intensities when animals undergo spontaneous shift between fast-wave and slow-wave states (Murakami
A

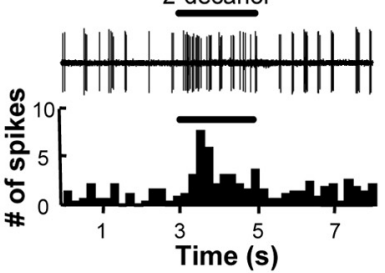

C

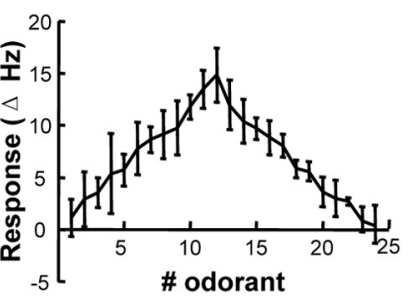

B

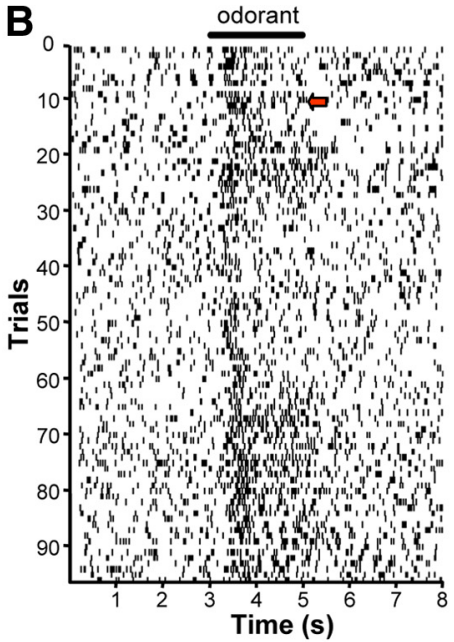

D
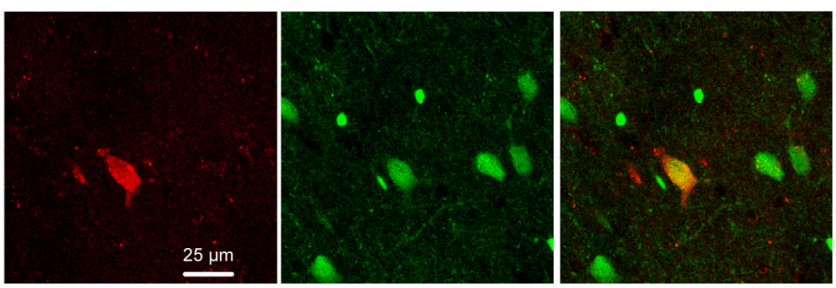

E

$\mathbf{F}$

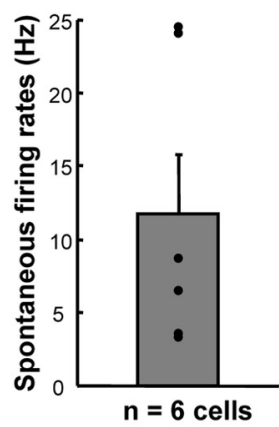

G

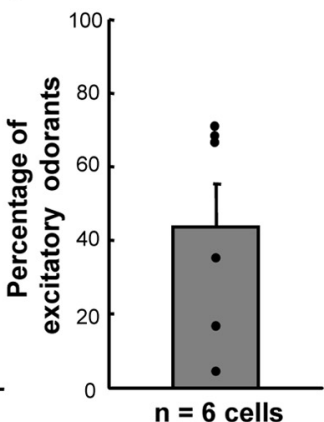

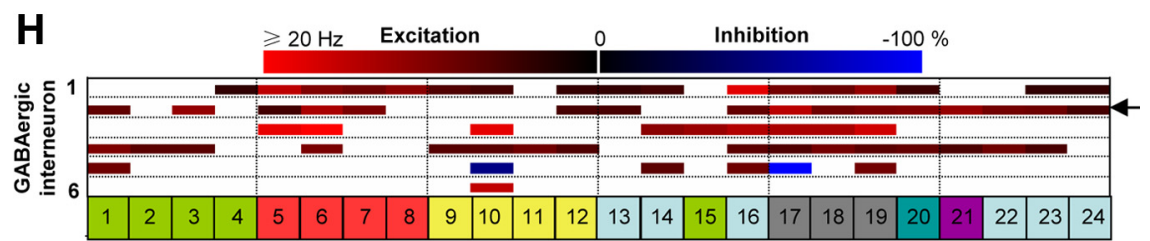

Figure 8. GABAergic neurons are spontaneously active and broadly excited by test odorants. $\boldsymbol{A}$-- $\boldsymbol{D}$, A representative GABAergic neuron. $\boldsymbol{A}$, Physiological trace and PSTH show strong activation of the cell by $1 \% 2$-decanol. $\boldsymbol{B}, \boldsymbol{C}$, Raster plot $(\boldsymbol{B})$ and tuning curve $(\boldsymbol{C})$ of the cell. Arrow in $\boldsymbol{B}$ points to the responses to 2-decanol. $\boldsymbol{D}$, GFP expression in the labeled cell indicates that it is a GABAergic cell. $\boldsymbol{E}$, Composite drawing shows the soma location of recorded GABAergic cells in the layer 3 of the aPCX. $\boldsymbol{F}$, High spontaneous firing rates of GABAergic cells. $\boldsymbol{G}$, Typically high percentage of excitatory odorants. $\boldsymbol{H}$, Plot of response profiles for the six GABAergic neurons. Arrow at right points to the cell shown in $A-D$.

et al., 2005; Wilson, 2010). Ketamine leads to higher response intensities and lower selectivity in the olfactory bulb and induces slow oscillations in the olfactory cortex (Fontanini et al., 2003; Rinberg et al., 2006). In addition to the potential artifacts caused by anesthesia, it had also been difficult to identify cell types in vivo. Recordings have described very different physiological properties of various types of cortical neurons (Protopapas and Bower, 2000; Luna and Schoppa, 2008; Poo and Isaacson, 2009; Stokes and Isaacson, 2010), suggesting that cell-type information be important for our understanding of circuit mechanisms underlying olfactory signal processing. 
These confounding factors are eliminated or substantially reduced by the approach of single-cell recording and juxtacellular labeling from head-restrained, awake GAD67-GFP mice. First, recording from awake animals removes potential side effects of anesthetics. Second, juxtacellular labeling facilitates the classification of cell types based on neuronal morphology. Last, GFP expression in GAD67-GFP mice allows the identification of GABAergic neurons.

Our data reveal rich diversity in olfactory response profiles among different types of aPCX neurons. One-quarter of PNs (type I PNs) are excited broadly by odorants, whereas the rest of PNs (types II and III PNs) are rarely excited by odorants in our test panel. Explicit inhibition, as defined by suppression of action potential firing by odorant stimuli, is often observed from type II PNs. GABAergic neurons are excited by odorants with poor selectivity, whereas non-GABAergic nPNs are usually inhibited nonselectively by odorants.

These observations from awake mice are in several ways compatible with the response patterns recorded from anesthetized animals. For example, we find that aPCX PNs exhibit low spontaneous firing activity and display an overall excitatory ratio of $\sim 20 \%$. This matches well with what have been reported from the aPCX of anesthetized animals (Wilson, 2001; Rennaker et al., 2007; Yoshida and Mori, 2007; Poo and Isaacson, 2009; Stettler and Axel, 2009; Isaacson, 2010). Several studies have shown that piriform cortical neurons can be activated by structurally dissimilar odorants (Rennaker et al., 2007; Yoshida and Mori, 2007; Poo and Isaacson, 2009). Similarly, both type I PNs and GABAergic neurons in the aPCX of awake mice are excited by odorants belonging to different chemical groups. Functional heterogeneity has been suggested by recordings from unrestrained rats engaged in an olfactory discrimination task (McCollum et al., 1991), although cell types had not been differentiated in the early study.

Conversely, several of our findings are unexpected from the results reported by previous studies. The diverse response profiles of individual PNs suggest that PN can be further divided into at least three functional subtypes, each of which exhibits a characteristic selectivity pattern based on the profiles of excitatory and inhibitory responses. In contrast to the concept of "sparse" representation pattern, broad excitatory responses are observed from individual type I PNs, which consist of approximately one-quarter of recorded PNs. Unpredicted by the suggestion of odorant-evoked global inhibition by interneurons (Poo and Isaacson, 2009), broad inhibitory responses are only displayed by individual type II PNs, which also consist of approximately one-quarter of sampled PNs. Both excitatory and inhibitory responses are rarely observed from approximately one-half of PNs (type III PNs), suggesting that they respond extremely selectively in terms of excitation and inhibition. Finally, we have uncovered the pattern of broad inhibitions to a population of layer 3 non-GABAergic nPNs, which have not been characterized by previous recordings.

Our results strongly suggest that olfactory information is represented by functionally heterogeneous populations of PNs, including a substantial portion of broadly tuned PNs and a majority of highly selective PNs. In addition, inhibition may contribute to the encoding scheme, because odorants can evoke clear suppression of action potential firing from more than one-quarter PNs and a majority of non-GABAergic nPNs.

\section{Potential circuitry mechanisms underlying the functional diversity in the aPCX}

Mitral/tufted cells in the olfactory bulb tend to be selectively excited by a small set of structurally similar odorants (Davison and Katz, 2007; Tan et al., 2010). It has been suggested that individual neurons in the piriform cortex integrate input from mitral/tufted cells associated with different glomeruli (Wilson, 2001; Stettler and Axel, 2009). This view is consistent with our finding that type I PNs are excited by structurally dissimilar odorants. The broad tuning of these type I PNs may be produced by either strong and nonselective excitatory inputs from many mitral/tufted cells and/or robust recurrent excitatory connections within the aPCX (Haberly, 2001; Franks and Isaacson, 2006). The high selectivity of a majority of PNs (types II and III PNs) can be achieved by several possible mechanisms. One possibility is that these selective PNs receive weak excitatory inputs from mitral/ tufted cells, and they can be only activated by synchronous activation of many glomeruli. Second, these cells may be intrinsically less excitable and thus have high threshold for action potential firing. Finally, their response tuning may be sharpened by strong inhibitions from GABAergic interneurons within the aPCX (Poo and Isaacson, 2009).

What contributes to the considerable variability in the profiles of inhibitory responses among subtypes of PNs? Whole-cell recordings from anesthetized rats show that odors produce inhibitory postsynaptic responses in $\sim 50 \%$ of PNs (Poo and Isaacson, 2009). This observation is consistent with our data showing that type II PNs are inhibited by a wide array of odorants and GABAergic neurons are broadly tuned. Conversely, the inhibitory tuning is very narrow for a majority of PNs, and the overall inhibition ratio is $<20 \%$ when all odor-cell pairs are considered. Extracellular recording precludes us from detecting inhibition at the subthreshold level. Nevertheless, the drastic variability in the extent of odor-evoked inhibition suggests that intracortical inhibitions may not be sufficiently strong for most of PNs to cause strong suppression of action potential firing.

It has been suggested that interneurons receive convergent excitatory inputs (Poo and Isaacson, 2009). The aPCX consists of multiple classes of interneurons, each of which is characterized by unique molecular markers and morphologies (C. Zhang et al., 2006; Suzuki and Bekkers, 2010a,b). The broad excitatory tuning of GABAergic neurons in awake mice suggests that these neurons may receive broad odor-evoked excitations. Nevertheless, excitatory responses are found only in $\sim 50 \%$ odor-cell pairs, suggesting that excitatory inputs to GABAergic neurons are not ubiquitously strong to induce spiking responses. Non-GABAergic nPNs represent another major class of interneurons in the aPCX. Unlike GABAergic neurons, they typically exhibit a broad inhibitory tuning. It is possible that non-GABAergic nPNs receive strong inhibitory input from GABAergic neurons. Both GABAergic and non-GABAergic interneurons can be divided into subclasses (Neville and Haberly, 2004). Future studies on the functional roles of specific classes of cortical interneurons will enhance our understanding on the mechanisms of signal processing by the intracortical circuits.

\section{References}

Buck L, Axel R (1991) A novel multigene family may encode odorant receptors: a molecular basis for odor recognition. Cell 65:175-187.

Davison IG, Katz LC (2007) Sparse and selective odor coding by mitral/ tufted neurons in the main olfactory bulb. J Neurosci 27:2091-2101.

Dombeck DA, Khabbaz AN, Collman F, Adelman TL, Tank DW (2007) Imaging large-scale neural activity with cellular resolution in awake, mobile mice. Neuron 56:43-57.

Ekstrand JJ, Domroese ME, Feig SL, Illig KR, Haberly LB (2001) Immuno- 
cytochemical analysis of basket cells in rat piriform cortex. J Comp Neurol 434:308-328.

Fontanini A, Spano P, Bower JM (2003) Ketamine-xylazine-induced slow $(<1.5 \mathrm{~Hz})$ oscillations in the rat piriform (olfactory) cortex are functionally correlated with respiration. J Neurosci 23:7993-8001.

Franks KM, Isaacson JS (2006) Strong single-fiber sensory inputs to olfactory cortex: implications for olfactory coding. Neuron 49:357-363.

Friedberg MH, Lee SM, Ebner FF (1999) Modulation of receptive field properties of thalamic somatosensory neurons by the depth of anesthesia. J Neurophysiol 81:2243-2252.

Godfrey PA, Malnic B, Buck LB (2004) The mouse olfactory receptor gene family. Proc Natl Acad Sci U S A 101:2156-2161.

Haberly LB (1983) Structure of the piriform cortex of the opossum. I. Description of neuron types with Golgi methods. J Comp Neurol 213:163-187.

Haberly LB (2001) Parallel-distributed processing in olfactory cortex: new insights from morphological and physiological analysis of neuronal circuitry. Chem Senses 26:551-576.

Illig KR, Haberly LB (2003) Odor-evoked activity is spatially distributed in piriform cortex. J Comp Neurol 457:361-373.

Isaacson JS (2010) Odor representations in mammalian cortical circuits. Curr Opin Neurobiol 20:328-331.

Kreher SA, Mathew D, Kim J, Carlson JR (2008) Translation of sensory input into behavioral output via an olfactory system. Neuron 59:110-124.

Litaudon P, Amat C, Bertrand B, Vigouroux M, Buonviso N (2003) Piriform cortex functional heterogeneity revealed by cellular responses to odours. Eur J Neurosci 17:2457-2461.

Luna VM, Schoppa NE (2008) GABAergic circuits control input-spike coupling in the piriform cortex. J Neurosci 28:8851-8859.

Malnic B, Hirono J, Sato T, Buck LB (1999) Combinatorial receptor codes for odors. Cell 96:713-723.

McCollum J, Larson J, Otto T, Schottler F, Granger R, Lynch G (1991) Short-latency single unit processing in olfactory cortex. J Cogn Neurosci 3:293-299.

Mombaerts P, Wang F, Dulac C, Chao SK, Nemes A, Mendelsohn M, Edmondson J, Axel R (1996) Visualizing an olfactory sensory map. Cell $87: 675-686$.

Mori K, Nagao H, Yoshihara Y (1999) The olfactory bulb: coding and processing of odor molecule information. Science 286:711-715.

Murakami M, Kashiwadani H, Kirino Y, Mori K (2005) State-dependent sensory gating in olfactory cortex. Neuron 46:285-296.

Neville KR, Haberly LB (2004) Olfactory cortex. In: The synaptic organization of the brain, Ed 5 (Shepherd GM, ed), pp 415-454. New York: Oxford UP.

Niell CM, Stryker MP (2010) Modulation of visual responses by behavioral state in mouse visual cortex. Neuron 65:472-479.

Pinault D (1996) A novel single-cell staining procedure performed in vivo under electrophysiological control: morpho-functional features of juxtacellularly labeled thalamic cells and other central neurons with biocytin or Neurobiotin. J Neurosci Methods 65:113-136.

Poo C, Isaacson JS (2009) Odor representations in olfactory cortex: "sparse" coding, global inhibition, and oscillations. Neuron 62:850-861.

Price JL, Powell TP (1970) The mitral and short axon cells of the olfactory bulb. J Cell Sci 7:631-651.

Protopapas AD, Bower JM (2000) Physiological characterization of layer III non-pyramidal neurons in piriform (olfactory) cortex of rat. Brain Res 865:1-11.

Rennaker RL, Chen CF, Ruyle AM, Sloan AM, Wilson DA (2007) Spatial and temporal distribution of odorant-evoked activity in the piriform cortex. J Neurosci 27:1534-1542.

Ressler KJ, Sullivan SL, Buck LB (1993) A zonal organization of odorant receptor gene expression in the olfactory epithelium. Cell 73:597-609.
Ressler KJ, Sullivan SL, Buck LB (1994) Information coding in the olfactory system: evidence for a stereotyped and highly organized epitope map in the olfactory bulb. Cell 79:1245-1255.

Rinberg D, Koulakov A, Gelperin A (2006) Sparse odor coding in awake behaving mice. J Neurosci 26:8857-8865.

Rubin BD, Katz LC (1999) Optical imaging of odorant representations in the mammalian olfactory bulb. Neuron 23:499-511.

Schoenbaum G, Eichenbaum H (1995) Information coding in the rodent prefrontal cortex. I. Single-neuron activity in orbitofrontal cortex compared with that in pyriform cortex. J Neurophysiol 74:733-750.

Shepherd GM, Chen WR, Greer CA (2004) Olfactory bulb. In: The synaptic organization of the brain, Ed 5 (Shepherd GM, ed), pp 165-216. New York: Oxford UP.

Soucy ER, Albeanu DF, Fantana AL, Murthy VN, Meister M (2009) Precision and diversity in an odor map on the olfactory bulb. Nat Neurosci 12:210-220.

Stettler DD, Axel R (2009) Representations of odor in the piriform cortex. Neuron 63:854-864.

Stokes CC, Isaacson JS (2010) From dendrite to soma: dynamic routing of inhibition by complementary interneuron microcircuits in olfactory cortex. Neuron 67:452-465.

Suzuki N, Bekkers JM (2010a) Distinctive classes of GABAergic interneurons provide layer-specific phasic inhibition in the anterior piriform cortex. Cereb Cortex. Advance online publication. Retrieved November 4, 2010. doi: 10.1093/cercor/bhq046.

Suzuki N, Bekkers JM (2010b) Inhibitory neurons in the anterior piriform cortex of the mouse: classification using molecular markers. J Comp Neurol 518:1670-1687.

Tamamaki N, Yanagawa Y, Tomioka R, Miyazaki J, Obata K, Kaneko T (2003) Green fluorescent protein expression and colocalization with calretinin, parvalbumin, and somatostatin in the GAD67-GFP knock-in mouse. J Comp Neurol 467:60-79.

Tan J, Savigner A, Ma M, Luo M (2010) Odor information processing by the olfactory bulb analyzed in gene-targeted mice. Neuron 65:912-926.

Uchida N, Takahashi YK, Tanifuji M, Mori K (2000) Odor maps in the mammalian olfactory bulb: domain organization and odorant structural features. Nat Neurosci 3:1035-1043.

Vassar R, Chao SK, Sitcheran R, Nuñez JM, Vosshall LB, Axel R (1994) Topographic organization of sensory projections to the olfactory bulb. Cell 79:981-991.

Wachowiak M, Cohen LB (2001) Representation of odorants by receptor neuron input to the mouse olfactory bulb. Neuron 32:723-735.

Wilson DA (1998) Habituation of odor responses in the rat anterior piriform cortex. J Neurophysiol 79:1425-1440.

Wilson DA (2000) Comparison of odor receptive field plasticity in the rat olfactory bulb and anterior piriform cortex. J Neurophysiol 84:30363042.

Wilson DA (2001) Receptive fields in the rat piriform cortex. Chem Senses 26:577-584.

Wilson DA (2010) Single-unit activity in piriform cortex during slow-wave state is shaped by recent odor experience. J Neurosci 30:1760-1765.

Yokoi M, Mori K, Nakanishi S (1995) Refinement of odor molecule tuning by dendrodendritic synaptic inhibition in the olfactory bulb. Proc Natl Acad Sci U S A 92:3371-3375.

Yoshida I, Mori K (2007) Odorant category profile selectivity of olfactory cortex neurons. J Neurosci 27:9105-9114.

Zhang C, Szabó G, Erdélyi F, Rose JD, Sun QQ (2006) Novel interneuronal network in the mouse posterior piriform cortex. J Comp Neurol 499:1000-1015.

Zhang X, Firestein S (2007) Comparative genomics of odorant and pheromone receptor genes in rodents. Genomics 89:441-450. 